\title{
Interação fraternal quando um irmão tem síndrome de Down: um estudo observacional
}

Bruna Rocha de Almeida*

Nara Liana Pereira-Silva**

\section{Resumo}

A qualidade da interação entre irmãos tem sido investigada há mais de três décadas. Entretanto, poucos estudos focalizam a díade irmão com síndrome de Down - irmão com desenvolvimento típico, especialmente no Brasil. Este estudo teve como objetivo descrever a interaçáo entre nove díades de irmãos, com idades entre quatro e 13 anos, tendo um deles a síndrome de Down. Foram gravadas, nas residências das díades, 27 sessões de observação do comportamento, totalizando 216 minutos. A análise das interações focalizou conteúdo e qualidade dos episódios, bem como categorias comportamentais de comando e responsividade. As díades se envolveram, principalmente, em atividades lúdicas, de forma 'Conjunta', com 'Amistosidade' e 'Sincronia'. As interaçôes tiveram 'Supervisão', 'Liderança' e emissão de comportamentos de comando do irmão com desenvolvimento típico. Pode-se afirmar que, nessas famílias, a interação fraternal é caracterizada pela assimetria de papéis e positividade, não sendo prejudicada pela presença do irmão com síndrome de Down.

Palavras-chave: Relação fraternal; Síndrome de Down; Metodologia observacional.

\footnotetext{
* Doutora em Psicologia pela Universidade Federal de Juiz de Fora (UFJF).Juiz de Fora, Minhas Gerais, Brasil.

** Doutora em Psicologia pela Universidade de Brasília, Brasília, Distrito Federal, Brasil.
} 


\section{Fraternal interaction when a sibling has Down syndrome: an observational study}

\section{Abstract}

The quality of interaction between siblings has been investigated for more than three decades. However, few studies focus on the dyad between a sibling with Down syndrome - sibling with typical development, especially in Brazil. This study aimed to describe the interaction among nine dyads of siblings, between four and 13 years old, in which one of them has Down syndrome. In the households of the dyads, 27 sessions of behavioral observation were recorded, totaling 216 minutes. The analysis of the interactions focused on content and quality of the episodes as well as the behavioral categories of command and responsiveness. The dyads engaged primarily in leisure activities, 'Jointly', with 'Friendliness' and 'Synchronicity'. The interactions had 'Supervision', 'Leadership' and command behaviors that were issued by the sibling with typical development. It can be said that in these families, fraternal interaction is characterized by the asymmetry of roles and positivity, not being harmed by the presence of the sibling with Down syndrome.

Keywords: Sibling relationship; Down syndrome; Observational methodology.

\section{Introdução}

A relação fraternal pode ser considerada uma das relaçóes sociais mais importantes, afinal, ela tende a ser a relação mais longa na vida do indivíduo. $\mathrm{Na}$ infância e na adolescência os irmãos aprendem juntos diversas habilidades sociais que lhes serão úteis pelo resto da vida, tais como cooperar, negociar, manejar conflitos e competir (HOWE; RECCHIA, 2006; SENNER; FISH, 2012). Na vida adulta, os irmãos são uma importante fonte de apoio emocional e financeiro uns dos outros (GOLDSMID; FÉRES-CARNEIRO, 2007).

Embora se observe um aumento no número de estudos acerca do subsistema fraternal em famílias com pessoas com síndrome de Down (SD), pouco se sabe sobre os padrôes de interaçáo desenvolvidos pelas díades de irmãos. A maior parte da literatura existente se refere aos efeitos que a convivência com o irmão com deficiência pode ocasionar no irmão com desenvolvimento típico (DT). Alguns estudos, por exemplo, indicam efeitos negativos, tais como isolamento social, estresse, depressão e privação da atenção dos genitores (NÚNEZ; RODRIGUES, 2005; STONEMAN, 2005). Outros demonstram efeitos positivos dessa convivência, a saber, os irmãos com DT tendem a ser mais empáticos, pacientes, tolerantes e perseverantes (BURKE, 2010; INAM; ZEHRA, 2012; LIZASOÁIN, 2009). Há ainda alguns estudos que indicam que os irmãos podem ter tanto respostas positivas quanto negativas à convivência com o irmão com deficiência (DYKENS, 2006; IRIARTE; IBARROLAGARCÍA, 2010). 
As pesquisas que tratam especificamente sobre as interaçóes e as relaçóes fraternais em famílias com pessoas com SD ainda são escassas, especialmente na América Latina. As investigaçôes sobre o tema demonstram que o irmão com DT, independente da idade e da ordem de nascimento, tende a assumir o papel de irmáo mais velho na relação, apresentando comportamentos de cuidado, ajuda e monitoria/ensino (ABRAMOVITCH; STANHOPE; PEPLER; CORTER, 1987; KUO, 2014). Ademais, observa-se a tendência de os irmãos com DT assumirem a supervisão e a liderança durante os episódios interativos, apresentando comportamentos diretivos (PEREIRA-SILVA, 2003; STONEMAN, 2005). O irmão com SD, por sua vez, tende a desempenhar o papel de submisso, a ter menos iniciativas durante a interação e a imitar o irmão com DT (ABRAMOVITCH et al., 1987; KNOTT; LEWIS; WILLIAMS, 2007). Quando o irmáo com SD apresenta menos competência social e cognitiva, há a tendência de os irmãos desempenharem papéis mais assimétricos à medida que eles crescem, seguindo uma trajetória não normativa (STONEMAN, 2009).

Além disso, a relação fraternal tem sido descrita pela literatura como sendo positiva, com características de amizade, afeto, companheirismo, amistosidade e sincronia (GRISANTE; AIELLO, 2012; PEREIRA-SILVA, 2003; ROPER; ALLRED; MANDLECO; FREEBORN; DYCHES, 2014; SENNER; FISH, 2012). Os irmãos de crianças com SD se apresentam como mais afetuosos e tolerantes nas interaçóes, sendo menos competitivos e menos propensos a interagir agressivamente com seus irmãos, quando comparados a díades de irmãos com DT (KAMINSKY; DEWEY, 2001). Em consonância, estudos indicam baixa taxa de conflito entre os irmãos durante as interaçôes (PEREIRA, 2003; GRIOT; POUSSIN; OSIURAK, 2013). Dessa forma, a presença de um irmão com SD não necessariamente implica em uma relação fraternal problemática. No entanto, há alguns fatores de risco que podem influenciar a qualidade da relaçáo fraternal, tais como o excesso de responsabilidade de cuidado com o irmão e o tratamento parental diferencial (STONEMAN, 2005).

Diante do pequeno número de estudos sobre a temática, especialmente no Brasil, e da importância da relação entre irmãos para o desenvolvimento (por exemplo: emocional, social) das pessoas, este artigo tem como objetivo descrever a interação entre díades de irmáos, tendo um deles o diagnóstico de síndrome de Down.

\section{Método}

\section{Participantes}

Participaram deste estudo nove famílias compostas por pai, mãe, um filho com diagnóstico de SD e um filho com DT. Todas as famílias residiam em uma cidade com cerca de 600 mil habitantes do interior do estado de Minas Gerais - Brasil. A média de idade das mães era de 42 anos e dos pais de 46 anos. Tanto os irmãos com SD como aqueles com DT tinham idade entre 4 e 13 anos. No entanto, a média da idade dos participantes com SD foi de 7,8 anos e daqueles com DT foi de 8,8 anos. A diferença mínima de idade entre os irmãos era de 11 meses e a máxima era de 5 anos e três meses. Cinco participantes com SD eram do sexo feminino e quatro do 
sexo masculino. Em relação aos irmãos com DT, seis eram do sexo feminino e três do sexo masculino. No que se refere à composição das díades, quatro irmãos com SD eram primogênitos e cinco eram caçulas. Seis díades eram compostas por irmãos do mesmo sexo. Quatro irmãos com SD e três com DT frequentavam a educação infantil e cinco irmãos com SD e seis com DT frequentavam o ensino fundamental. $\mathrm{Na}$ Tabela 1 podem ser visualizadas as características das díades de irmãos participantes deste estudo.

Tabela 1 - Idade, sexo e tipo de escola frequentada pelos irmãos com síndrome de Down e com desenvolvimento típico ${ }^{1}$

\begin{tabular}{|c|c|c|c|c|c|c|}
\hline \multirow[b]{2}{*}{ Díade } & \multicolumn{2}{|c|}{ Idadea } & \multicolumn{2}{|c|}{ Sexo $^{b}$} & \multicolumn{2}{|c|}{ Tipo de escola } \\
\hline & ISD & IDT & ISD & IDT & ISD & IDT \\
\hline 1 & $4 a 2 m$ & $5 a 4 m$ & M & $\mathrm{F}$ & $\mathrm{El}$ & $\mathrm{El}$ \\
\hline 2 & $5 a$ & $10 \mathrm{a} 2 \mathrm{~m}$ & $\mathrm{~F}$ & $\mathrm{~F}$ & El & $\mathrm{EF}$ \\
\hline 3 & $5 a 1 m$ & $4 a 2 m$ & $\mathrm{~F}$ & $\mathrm{~F}$ & $\mathrm{El}$ & $\mathrm{El}$ \\
\hline 4 & $6 a 1 m$ & $10 \mathrm{a} 3 \mathrm{~m}$ & $\mathrm{~F}$ & $\mathrm{~F}$ & El & $\mathrm{EF}$ \\
\hline 5 & $8 a$ & $13 a 3 m$ & M & $\mathrm{F}$ & EF & $\mathrm{EF}$ \\
\hline 6 & $8 a 11 m$ & $4 a 10 m$ & $\mathrm{~F}$ & $\mathrm{~F}$ & $\mathrm{EF}$ & $\mathrm{El}$ \\
\hline 7 & $10 \mathrm{a} 10 \mathrm{~m}$ & $13 a 6 m$ & M & M & EF & $\mathrm{EF}$ \\
\hline 8 & $11 \mathrm{a} 2 \mathrm{~m}$ & $6 a 3 m$ & $\mathrm{~F}$ & M & EF & $\mathrm{EF}$ \\
\hline 9 & $13 a 5 m$ & $9 a 11 m$ & M & $M$ & EF & $\mathrm{EF}$ \\
\hline
\end{tabular}

\section{Instrumento/técnica}

Para o registro das interaçóes foi utilizada técnica de observação do comportamento em ambiente natural. Optou-se por realizar três sessóes de observaçáo do comportamento com duraçáo de oito minutos cada e com intervalo de um mês entre elas, a fim de verificar possíveis padrōes de interação das díades de irmãos. As sessóes foram gravadas utilizando a tecnologia de vídeo, por meio de uma filmadora digital. O objetivo principal das observações foi registrar as interações desenvolvidas entre os irmãos, quando a principal tarefa era "interagir", ou seja, quando os irmãos se encontravam em atividades livres. De acordo com Dessen (1994), a 'atividade livre' é apropriada para registrar as interações, sobretudo quando o objetivo da pesquisa é o registro de padróes de interação familiar em situação natural. A 'atividade livre' pode ser definida como toda e qualquer atividade de lazer, como por exemplo, assistir à televisão, brincar e contar histórias. Destaca-se que a utilização da tecnologia de vídeo permite obter um registro seguro da situaçáo observada, o que propicia uma descrição mais rica e fidedigna da interaçáo, quando comparada ao registro sem o uso dessa técnica (KREPPNER, 2011). 


\section{Procedimentos}

Após a aprovação do presente estudo pelo Comitê de Ética e Pesquisa, sob no 102.942, as pesquisadoras entraram em contato com escolas e instituições de Educação Especial para o recrutamento das crianças/adolescentes com SD. Após selecionadas as crianças/adolescentes com SD, suas famílias foram contatadas, tratando-se, portanto, de uma amostra de conveniência. No total, foram selecionadas 13 famílias com apenas dois filhos(as), sendo um com SD e outro(a) com DT residindo na mesma casa, junto com os genitores. Três famílias não aceitaram participar da pesquisa devido à falta de tempo. Assim, dez famílias iniciaram a participação na pesquisa. Durante a coleta de dados, uma família desistiu de participar em razáo do divórcio dos genitores. Assim, a amostra foi constituída por nove famílias.

A coleta de dados foi realizada na residência da família em três visitas, com intervalo médio de um mês entre elas. A primeira visita incluiu: (a) assinatura do Termo de Consentimento Livre e Esclarecido (TCLE) pelos genitores e (b) gravação em vídeo da primeira sessão de observação do comportamento da díade de irmãos. Um mês após, foi realizada a gravação da $2^{\text {a }}$ sessão de observação e, posteriormente, na terceira visita, foi gravada a $3^{\text {a }}$ sessão de observação da díade de irmãos, totalizando 27 sessóes e 216 minutos de observaçáo, com média de 8 minutos por sessáo.

Para a análise dos dados observacionais, foi realizado o mapeamento das gravaçóes utilizando-se a técnica de Registro de Evento (FAGUNDES, 1941/2002). A utilização dessa técnica prevê que, primeiramente, sejam definidos os comportamentos a serem observados. No presente trabalho, para a análise dos comportamentos, utilizou-se o sistema de categoria proposto por Pereira-Silva (2003) que considera: (1) o conteúdo das interaçôes; (2) a estrutura da interação; (3) a qualidade dos episódios interacionais; e, (4) as categorias comportamentais. Segundo Hinde (1979/1997), o 'conteúdo' das interaçôes são as atividades desenvolvidas pelas pessoas, ou seja, o que os irmáos fazem quando estáo juntos. A 'estrutura de participaçáo' se refere à maneira como as pessoas se engajam nas atividades durante os episódios interacionais, podendo ser de forma 'conjunta', 'paralela' ou 'individual'. A 'forma' como os participantes realizam as atividades refere-se à 'qualidade' das interaçôes, por exemplo, a afetividade nas interaçôes. No que tange às 'categorias comportamentais', estas foram definidas pela emissão de comportamentos de comando de um membro em relação ao outro (por exemplo: solicitar/sugerir, ordenar e proibir) e comportamentos de responsividade (por exemplo: obedecer ou rejeitar a sugestáo ou a ordem). O Dicionário de Categorias Observacionais, bem como o protocolo de registro utilizado podem ser encontrados em Almeida (2014).

Os dados observacionais foram analisados utilizando-se frequências relativas e percentuais. $\mathrm{O}$ índice de concordância entre observadores foi calculado com base no registro realizado por outro observador treinado em Observação do Comportamento que registrou $10,4 \%$ das sessôes de observação, efetuando-se o cálculo das concordâncias e discordâncias, a partir da proposta de Fagundes (1941/2002). Os índices obtidos na concordância entre-observadores foram: (a) atividades realizadas: 96,7\%; (b) estrutura de participação: 83,8\%; (c) qualidade das interaçôes: 38,5\%; (d) categorias comportamentais: $93,8 \%$. O índice global encontrado foi de 75,6\%. 


\section{Resultados}

\section{Conteúdo das interações: atividades desenvolvidas pelos irmãos}

As atividades desenvolvidas com mais frequência pelos irmãos em situação de atividade livre foram as 'Brincadeiras' (61,5\%), seguidas por 'Jogos' (27,7\%), 'Assistir à televisão' (5,5\%), 'Conversar' (2,9\%), 'Socializar' (2,0\%) e 'Cantar' (0,4\%). Em específico, os tipos de 'Brincadeiras' mais frequentes foram 'Brincadeiras com objetos' $(25,2 \%)$, 'Brincadeira de atividades escolares' $(14,7 \%)$ e 'Brincadeiras envolvendo coordenação motora global' (9,2\%). Já o tipo de 'Jogos' mais frequente foi o 'Jogos diversos' $(27,7 \%)$. A Figura 1 apresenta as três atividades específicas desenvolvidas com maior frequência nas sessôes de observação: 'Brincadeira com objeto', 'Jogos diversos' e 'Brincadeira de atividades escolares'.

Figura 1 - Frequências relativas das atividades desenvolvidas com maior frequência pelos irmãos

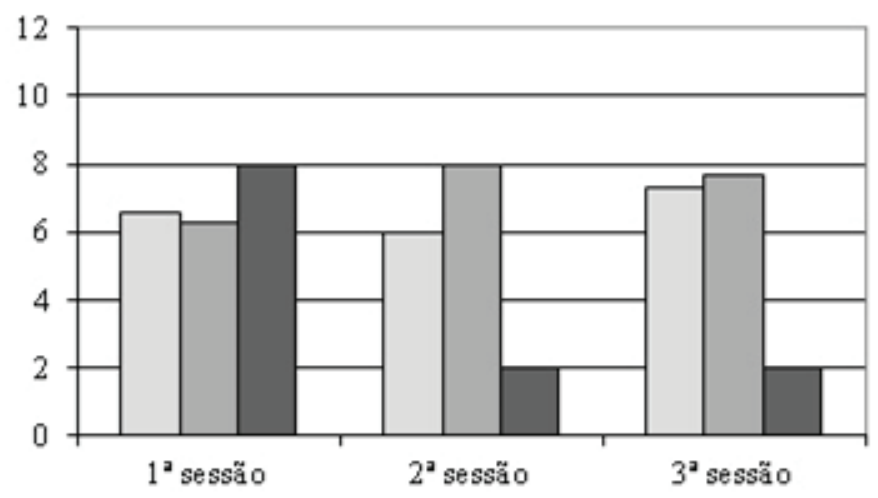

Figura 1 (continuação) - Frequências relativas das atividades desenvolvidas com maior frequência pelos irmãos

\section{口Brincadeiras com objetos}

a Jogos diversos

arinca deiras de atividades escolares 


\section{Estrutura de participação}

No tocante à estrutura de participação, a 'Conjunta' foi desenvolvida com maior frequência (67,1\%), seguida por 'Paralela' (20,9\%) e 'Individual' (12,0\%). No que se refere a cada uma das três sessốes observacionais, nota-se que a estrutura 'Conjunta' foi o tipo mais frequente na $1^{\mathrm{a}}, 2^{\mathrm{a}}$ e $3^{\mathrm{a}}$ sessão, respectivamente $64,9 \%, 75,7 \%$ e $61,5 \%$, tendo a estrutura 'Paralela' um percentual de $18,6 \%, 17,9 \%$ e $26,5 \%$, respectivamente na $1^{\text {a }}, 2^{\text {a }}$ e $3^{\text {a }}$ sessão. A estrutura 'Individual' foi a menos frequente ao longo do tempo, apresentando $16,5 \%$ na $1^{\text {a }}$ sessão, $6,4 \%$ e $12,0 \%$ nas $2^{\text {a }}$ e $3^{\text {a }}$ sessóes.

\section{Qualidade da interação}

As interações entre os irmãos foram caracterizadas por 'Sincronia' $(98,4 \%)$, 'Amistosidade' (95,9\%), 'Liderança' (77,5\%) e 'Supervisão' (57,4\%). Os dados observacionais da qualidade da interação fraternal podem ser observados na Tabela 2, que apresenta as frequências relativas e os percentuais das categorias referentes às dimensôes da qualidade das interações desenvolvidas nas $1^{\mathrm{a}}, 2^{\mathrm{a}}$ e $3^{\mathrm{a}}$ sessốes.

Tabela 2 - Frequências relativas e percentuais da qualidade da interação fraternal nas três sessōes de observação ${ }^{2}$

\begin{tabular}{lcccccccc} 
& \multicolumn{8}{c}{ Sessões de observação } \\
\cline { 2 - 10 } $\begin{array}{l}\text { Qualidade da } \\
\text { interação }\end{array}$ & $\mathrm{N}$ & $1^{\mathrm{a}}$ & \multicolumn{2}{c}{$2^{\mathrm{a}}$} & \multicolumn{3}{c}{$3^{\mathrm{a}}$} & \multicolumn{2}{c}{ Total } \\
\hline Sincronia & 52,7 & 95,8 & 40,3 & 100 & 48 & 100 & 141 & 98,4 \\
Sem sincronia & 2,3 & 4,2 & - & - & - & - & 2,3 & 1,6 \\
\hline & & & & & & & & \\
Amistosidade & 50,7 & 92,2 & 40 & 99,3 & 46,7 & 97,3 & 137,4 & 95,9 \\
Conflito & 4,3 & 7,8 & 0,3 & 0,7 & 1,3 & 2,7 & 5,9 & 4,1 \\
\hline & & & & & & & & \\
Supervisão & 33,3 & 60,5 & 19,3 & 47,9 & 29,7 & 61,9 & 82,3 & 57,4 \\
Sem supervisão & 21,7 & 39,5 & 21 & 52,1 & 18,3 & 38,1 & 61 & 42,6 \\
\hline & & & & & & & & \\
Com liderança & 43,3 & 78,7 & 30 & 74,4 & 37,7 & 78,5 & 111 & 77,5 \\
Sem liderança & 11,7 & 21,3 & 10,3 & 25,6 & 10,3 & 21,5 & 32,3 & 22,5 \\
\hline
\end{tabular}

No que se refere à dimensão 'Sincronia', observa-se que houve prevalência das interaçôes 'Com Sincronia' nas três sessôes de observação. Em relação à 'Afetividade', as interaçốes foram predominantemente caracterizadas por 'Amistosidade' nos três momentos de coleta de dados.

No tocante à dimensão 'Supervisão', verifica-se que houve maior frequência das interaçôes 'Com Supervisão' na primeira e terceira sessôes. Quando a interaçáo foi caracterizada pela supervisão de um irmão, houve predomínio da 'Supervisão' pelo irmão com DT $(87,5 \%)$ em relação ao irmão com SD (12,5\%).

Em relação à 'Liderança' durante as interações fraternais, observa-se que houve maior frequência das interaçôes desenvolvidas 'Com Liderança' de um dos irmãos. Quando a interação foi caracterizada por 'Com Liderança', foi observado o predomínio da 'Liderança' do irmão com DT (79,8\%) em relação ao irmão com SD $(20,2 \%)$. 
A Tabela 3 apresenta as frequências relativas e o percentual das categorias 'Supervisão' e 'Liderança' de acordo com cada irmáo quando em interação.

Tabela 3 - Frequências relativas e percentuais das categorias 'supervisão' e 'liderançà de acordo com cada irmão

\begin{tabular}{|l|c|c|}
\hline \multicolumn{1}{|c|}{ Ações educacionais e pedagógicas } & \multicolumn{2}{|c|}{ Favorável } \\
\cline { 2 - 3 } & $\mathrm{n}$ & $\%$ \\
\hline $\begin{array}{l}\text { Usar recursos e materiais pedagógicos para desenvolvimento } \\
\text { de habilidades e aprendizagem do aluno }\end{array}$ & 183 & 92 \\
\hline $\begin{array}{l}\text { Recomendar à família a necessidade de acompanhamento do } \\
\text { filho (a) por profissionais da saúde mental. }\end{array}$ & 182 & 91 \\
\hline $\begin{array}{l}\text { Avaliar periodicamente habilidades de aprendizagem do aluno } \\
\text { para que, com base nelas, planejar introdução de novas } \\
\text { habilidades. }\end{array}$ & 174 & 87 \\
\hline
\end{tabular}

\section{Comportamentos de comandos e de responsividade emitidos durante as interações}

Em relação aos comportamentos emitidos pelas díades, observou-se que o comportamento 'Solicitar/Sugerir' $(42,6 \%)$ foi emitido com mais frequência pelos irmãos, seguido pelos comportamentos de 'Obedecer solicitação' (29,7\%) e 'Rejeitar' $(14,1 \%)$. Os comportamentos de 'Proibir' $(2,6 \%)$ e 'Elogiar' (2,0\%) foram emitidos com menos frequência, sendo que $87,5 \%$ do comportamento 'Elogiar' e $95,5 \%$ do comportamento 'Proibir' foram emitidos pelo irmão com DT. Não foi observado o comportamento de imitação em nenhuma das sessōes de observação. Como demonstrado na Tabela 4, os irmãos com DT emitiram com mais frequência os comportamentos de comando, tanto os de 'Solicitar/Sugerir' (68,5\%), quanto os de 'Ordenar' (96,7\%) e 'Proibir' (95,5\%), quando comparados com os irmãos com SD. Esse padrão de comportamento foi observado nas três fases de coleta de dados.

No que se refere aos comportamentos de 'Responsividade', observa-se que os irmáos com SD emitiram com mais frequência o comportamento de 'Obedecer ordem' (100\%), 'Obedecer solicitação' $(68,6 \%)$ e 'Rejeitar' $(67,1 \%)$. A Tabela 4 apresenta as frequências e os percentuais dos comportamentos de comando e de responsividade emitidos pelos irmãos nas três fases de coleta de dados. 
Tabela 4 - Frequências relativas e percentuais das categoriais comportamentais de comando e de responsividade

\begin{tabular}{|c|c|c|c|c|c|c|c|c|}
\hline \multirow{2}{*}{$\begin{array}{l}\text { Categorias } \\
\text { comportamentais }\end{array}$} & \multicolumn{2}{|c|}{$1^{\natural}$ sessão } & \multicolumn{2}{|c|}{$2^{\mathrm{a}}$ sessão } & \multicolumn{2}{|c|}{$3^{\mathrm{a}}$ sessão } & \multicolumn{2}{|c|}{ Total } \\
\hline & $\mathrm{N}$ & $\%$ & $\mathrm{~N}$ & $\%$ & $\mathrm{~N}$ & $\%$ & $\mathrm{~N}$ & $\%$ \\
\hline \multicolumn{9}{|c|}{ Categorias de comando } \\
\hline Solicitar/Sugerir IDT & 14,7 & 55,1 & 31,7 & 88,8 & 29,7 & 61 & 76,1 & 68,5 \\
\hline Solicitar/Sugerir ISD & 12 & 44,9 & 4 & 11,2 & 19 & 39 & 35 & 31,5 \\
\hline Ordenar IDT & 9 & 92,8 & 7 & 100 & 4,3 & 100 & 20,3 & 96,7 \\
\hline Ordenar ISD & 0,7 & 7,2 & 0 & 0 & 0 & 0 & 0,7 & 3,3 \\
\hline Proibir IDT & 1,7 & 85 & 0,7 & 100 & 4 & 100 & 6,4 & 95,5 \\
\hline Proibir ISD & 0,3 & 15 & 0 & 0 & 0 & 0 & 0,3 & 4,5 \\
\hline \multicolumn{9}{|c|}{ Categorias de responsividade } \\
\hline $\begin{array}{l}\text { Obedecer solicitação } \\
\text { IDT } \\
\text { Obedecer solicitação }\end{array}$ & 5 & 29,4 & 2,3 & 10,2 & 17 & 45,1 & 24,3 & 31,4 \\
\hline & 12 & 70,6 & 20,3 & 89,8 & 20,7 & 54,9 & 53 & 68,6 \\
\hline Obedecer ordem IDT & - & - & - & - & - & - & - & - \\
\hline Obedecer ordem ISD & 4,7 & 100 & 0,7 & 100 & 3,3 & 100 & 8,7 & 100 \\
\hline Rejeitar IDT & 7,7 & 55 & 1,7 & 16,3 & 2,7 & 21,8 & 12,1 & 32,9 \\
\hline
\end{tabular}

O comportamento de 'Obedecer solicitação' foi emitido com mais frequência pelo irmão com SD, embora se observe um aumento da frequência de emissóes pelo irmão com DT ao longo das três sessôes. Os comportamentos de 'Obedecer ordem' foram emitidos apenas pelos irmãos com $\mathrm{SD}$, com maior frequência desse comportamento nas primeira e terceira sessôes de observação. Em relação ao comportamento de 'Rejeitar', observa-se que o irmão com SD emitiu esse comportamento com mais freqüência do que o irmão com DT nas segunda e terceira sessões de observação.

\section{Discussão}

A partir da análise dos dados observacionais, é possível concluir que as interaçôes entre os irmãos nas famílias investigadas são caracterizadas como positivas, conforme indica a literatura (ROPER et al., 2014; SENNER; FISH, 2012; STONEMAN, 2005). Os resultados deste estudo demonstram que a qualidade da interação é caracterizada por 'Sincronia' e 'Amistosidade', bem como que a estrutura de participação nas atividades é predominantemente 'Conjunta', corroborando os estudos brasileiros que utilizaram metodologia observacional e o mesmo sistema de categorias utilizado neste trabalho (GRISANTE; AIELLO, 2012; PEREIRA-SILVA, 2003). 
A análise dos dados sugere que, nas díades pesquisadas, houve o desempenho do papel diretivo do irmáo com DT, que assumiu a postura de irmão mais velho, conforme demonstram os estudos da área (ABRAMOVITCH et al., 1987; PEREIRA-SILVA, 2003; STONEMAN, 2009). A assimetria de papéis pode ser observada no fato de haver predomínio da emissão de comportamentos referentes à liderança e à supervisão pelo irmão com DT em relação ao irmão com SD. Em geral, o irmão com DT emitiu com maior frequência os comportamentos de 'Solicitar/Sugerir' e 'Ordenar' e o irmão com SD emitiu mais frequentemente os comportamentos de 'Obedecer', seja à solicitação ou à ordem dada pelo irmão. Ao mesmo tempo, o irmão com $\mathrm{SD}$ apresentou mais comportamentos de submissáo, assumindo, assim, a postura de irmão mais novo, o que é coerente com a literatura (KLEIN; FELDMAN; ZARUR, 2002; KUO, 2014). Abramovitch et al. (1987) indicam que uma explicação simples para o fato de o irmão com SD assumir papéis 'submissos' é que o seu repertório de comportamento e suas habilidades sociais e intelectuais seriam mais limitadas em razão da deficiência intelectual. De acordo com os autores, na relaçáo o que importa não é a ordem de nascimento e sim a diferença de habilidades entre os irmãos, sendo que, naturalmente, as diferenças nas habilidades tendem a ser maiores para díades em que a criança com SD é mais nova do que o irmáo com DT.

No tocante ao que os irmãos fazem quando estão juntos, verificou-se que as atividades desenvolvidas com mais frequência pelas díades foram as 'Lúdicas', em específico as 'Brincadeiras com objetos', os 'Jogos diversos' e as 'Brincadeiras de atividades escolares'. O predomínio das atividades lúdicas durante os episódios interativos foi destacado por Grisante e Aiello (2012) e Pereira-Silva (2003). O resultado é consoante com a literatura que aponta as brincadeiras como a principal atividade na infância (VIGOTSKI, 2008). No estudo comparativo de Pereira-Silva (2003), por exemplo, as díades de irmãos com DT também desenvolveram, com mais frequência, as atividades lúdicas.

Foi observado um decréscimo da frequência da atividade 'Brincadeiras de atividades escolares' ao longo das sessóes de observaçáo, sendo que na primeira fase de coleta essa atividade teve uma frequência alta em comparação com as demais fases. O que pode ter ocorrido para haver uma diminuição na frequência dessa atividade? Provavelmente, por não estarem acostumados com a pesquisadora/observadora responsável pela coleta de dados, os irmãos com DT queriam mostrar as capacidades dos irmãos com SD, afinal, aqueles sabiam que a pesquisadora era psicóloga, fato este que pode ter sido associado ao estereótipo da profissão, ou seja, o que analisa comportamentos. Além disso, frequentemente, os genitores mostravam para a pesquisadora o que o filho com SD era capaz de desempenhar ou relatavam sobre esses acontecimentos. Assim, parece que esse tipo de situação era comum entre os membros familiares. Outra explicação refere-se ao fato de, especialmente na primeira sessão, ter ocorrido maior interferência dos genitores nas atividades dos filhos, ora recomendando que o filho com DT fosse atencioso e tivesse cuidado com aquele com SD, ora direcionando a atividade antes do início da sessão de observação. Essa interferência também sugere a influência dos genitores nas relaçôes fraternais, conforme demonstra Brody (1998). 
Observou-se baixa frequência dos comportamentos de 'Proibir' e 'Elogiar'. Pereira-Silva (2003) também encontrou baixos índices do comportamento de 'Proibir' e ausência do comportamento de 'Elogiar', tanto em díades com irmãos com DT, quanto naquelas em que um dos irmãos tinha SD. Além disso, no presente estudo não foi observado o comportamento de 'Imitar' durante as sessôes de observação, embora estudos demonstrem que o irmão com SD imita o irmão com DT com maior frequência do que o irmão com DT imita o com SD (ABRAMOVITCH et al., 1987; KNOTT et al., 2007). A ausência do comportamento 'Imitar' pode ter ocorrido pelo fato de não se ter observado, durante os episódios interacionais, comportamentos igualmente emitidos simultaneamente, conforme consta na definição da categoria (ver ALMEIDA, 2014). Embora não tenha sido registrado, é importante destacar que em algumas díades foi possível identificar comportamentos similares, porém não simultâneos. Por exemplo, um irmão faz um círculo vermelho no papel e o outro, após alguns segundos, faz outro círculo.

Para avaliar a qualidade do registro observacional, um critério amplamente utilizado é o cálculo de concordância entre-observadores. De acordo com Fagundes (1941/2002), o índice ideal é aquele igual ou acima de 70\%. No entanto, em sistemas de categorias muito complexos, como o utilizado neste trabalho, são aceitáveis índices de $50 \%$ e $60 \%$ (M. A. DESSEN, comunicação pessoal, como citado por PEREIRASILVA, 2003). Segundo o índice geral alcançado nesse estudo, pode-se afirmar que houve uma concordância satisfatória entre os observadores. No entanto, observa-se um baixo índice para os dados da qualidade das interaçôes, o qual pode ter ocorrido em funçáo da natureza das categorias. Talvez uma das soluçóes para melhor garantir um índice mais aceitável seria definir melhor a unidade de análise, em especial a relativa à categoria 'Liderança', delimitando o início e término da unidade comportamental. Esse procedimento auxiliaria na classificação dos comportamentos observados, principalmente quando o observador tem pouco treinamento em metodologia observacional. Contudo, conforme explica Pereira-Silva (2003), a credibilidade dos dados de um estudo observacional não deve ser baseada unicamente no índice de concordância, já que este é apenas um dos fatores que, "juntamente com o rigor e os cuidados metodológicos referentes aos procedimentos adotados para coleta e análise dos dados, pode assegurar, com um pouco mais de precisão, a validade dos dados obtidos" (p.147). Apesar disso, a coleta de dados com 9 famílias pode ser apontada como uma limitação dessa investigação, não sendo possível qualquer generalização dos resultados. Destaca-se a dificuldade no recrutamento de famílias que atendessem ao critério de inclusão do presente estudo e a necessidade de estudos observacionais com amostras maiores para maior aprofundamento do objeto de estudo.

Outra questão que merece destaque é o fato de que o sistema de categorias observacionais capta o fluxo de interaçóes num momento específico, ou seja, é um dado de um recorte no tempo. Pesquisas longitudinais seriam úteis para a compreensão dos padróes de relação fraternal ao longo do tempo. Também seria interessante o estudo dos padrôes interativos de díades e tríades de irmãos de diferentes faixas etárias e que acompanhem os irmãos ao longo do curso de vida. Além disso, fazem-se necessários estudos comparativos com amostras compostas por irmãos com DT, bem como por irmãos com outras deficiências ou transtornos, a fim de verificar possíveis diferenças e semelhanças entre a relação fraternal nessas díades. 
Por fim, conclui-se que a interação fraternal não parece ser prejudicada pela presença de um irmáo com SD. Consoante com a literatura, os resultados deste estudo indicam que a interação entre os irmãos tende a ser amistosa e sincrônica, apresentando baixo nível de conflito. Embora o irmáo com DT apresente comportamentos diretivos na maior parte do tempo e ao longo das três sessóes de observação, liderando as atividades, a relação se manteve funcional, sendo desenvolvida de forma conjunta. Isso demonstra que, apesar da assimetria de papéis, os irmãos conseguem desenvolver atividades conjuntamente e com afetividade positiva. Este é um resultado importante que auxilia no movimento de desmistificação e diminuição do preconceito acerca das relaçôes estabelecidas nas famílias de pessoas com deficiência, em específico com SD.

\section{Referências}

ABRAMOVITCH, R. et al. The influence of Down's syndrome on sibling interaction. Journal of Child Psychology and Psychiatry and Allied Disciplines, v. 28, n. 6, p. 865-879, 1987.

ALMEIDA, B. R. Interaçóes fraternais em famílias de crianças e adolescentes com síndrome de Down. Dissertaçáo (Mestrado em Psicologia) - Programa de Pós-Graduação em Psicologia, Universidade Federal de Juiz de Fora, Juiz de Fora, 2014.

BRODY, G. H. Sibling relationship quality: Its causes and consequences. Annual Review of Psychology, v. 49, n. 1, p. 1-24, 1998.

BURKE, P. Brother and sisters of disabled children: The experience of disability by association. British Journal of Social Work, v. 40, n. 6, p. 1681-1699, 2010.

DESSEN, M. A. Interaçốes e relaçóes no contexto familiar: Questôes teóricas e metodológicas. Psicologia: Teoria e Pesquisa, v. 10, n. 2, p. 213-220, 1994.

DYKENS, E. M. Toward a positive psychology of mental retardation. American Journal of Orthopsychiatry, v. 76, n. 2, p. 185-193, 2006.

FAGUNDES, A. J. F. M. Descriçấo, definição e registro de comportamento. São Paulo: EDICON, $1941 / 2002$.

GOLDSMID, R.; FÉRES-CARNEIRO, T. A função fraterna e as vicissitudes de ter e ser um irmão. Psicologia em Revista, v. 13, n. 2, p. 293-308, 2007.

GRIOT, M.; POUSSIN, M.; OSIURAK, F. L'expérience fraternelle confrontée à la déficience intellectuelle. Pratiques Psychologiques, v. 19, n. 4, p. 245-263, 2013.

GRISANTE, P. C.; AIELLO, A. L. R. Interaçôes familiares: Observação de diferentes subsistemas em família com uma criança com síndrome de Down. Revista Brasileira de Educaçáo Especial, v. 18, n. 2, p. 195-212, 2012.

HINDE, R. A. Relationships: A dialectical perspective. London: Psychology Press, 1979/1997.

HOWE, N. I. N. A.; RECCHIA, H. O. L. L. Y. Sibling relations and their impact on children's development. In: TREMBLAY R. E.; BARR R. G.; PETERS R. D. (Orgs.). Encyclopedia on Early Childhood Development [online]. Montreal, Quebec: Centre of Excellence for Early Childhood Development; p. 1-8, 2006.

INAM, A.; ZEHRA, A. Effect of mentally retarded children on their non retarded female siblings (12-18 years). International Journal of Social Science, v. 1, n.1, p. 1-19, 2012.

IRIARTE, C.; IBARROLA-GARCÍA, S. Revisión de estudios sobre la vivencia emocional de la discapacidad intelectual por parte de los hermanos. Estudios sobre Educación, v. 19, p. 53-75, 2010.

KAMINSKY, L.; DEWEY, D. Siblings relationships of children with autism. Journal of Autism and Developmental Disorders, v. 31, n.4, p. 399-410, 2001.

KLEIN, P. S.; FELDMAN, R.; ZARUR, S. Mediation in a sibling context: The relations of older sibling's mediating behaviour and younger siblings' task performance. Infant and Child Development, v. 11, n.4, p. 321-333, 2002. 
KNOTT, F.; LEWIS, C.; WILLIAMS, T. Sibling interaction of children with autism: Development over 12 months. Journal of Autism Development Disorder, v.37, n.10, p. 1987-1995, 2007.

KREPPNER, K. Aplicando a metodologia de observaçáo em psicologia do desenvolvimento e da família. Traduçâo de Maria Auxiliadora Dessen. Curitiba: Juruá, 2011.

KUO, Y. C. Brothers' experiences caring for a sibling with Down syndrome. Qualitative health research, v. 24, n.8, p.1102-1113, 2014.

LIZASOÁIN, O. R. Discapacidad y familia: El papel de los hermanos. In El largo camino hacia una educación inclusiva: La educación especial y social del siglo XIX a nuestros días: XV Coloquio de Historia de la Educación. Simpósio realizado na Universidad Pública de Navarra, Pamplona-Iruñea. (2009, Julho).

NÚNEZ, B.; RODRÍGUEZ, L. Los hermanos com discapacidad: Una asignatura pendiente. Buenos Aires: Associación AMAR, 2005.

PEREIRA-SILVA, N. L. Famílias de crianças com e sem síndrome de Down: Um estudo comparativo das relaçóes familiares. Tese (Doutorado em Psicologia) - Programa em Pós-Graduação em Psicologia, Universidade de Brasília, Brasília, 2003.

ROPER, S. O. et al. Caregiver burden and sibling relationships in families raising children with disabilities and typically developing children. Families, Systems \& Health, v. 32, n.2, p. 241-246, 2014.

SENNER, J. E.; FISH, T. Comparison of child self-report and parent report on the sibling need and involvement profile. Remedial and Special Education, v. 33, n. 2, p. 103-109, 2012.

STONEMAN, Z. Siblings of children with disabilities: Research themes. Mental Retardation, v. 43, n. 5, p. 339-350, 2005.

STONEMAN, Z. Siblings of children with intellectual disabilities: Normal, average, or not too different?. International Review of Research in Mental Retardation, v. 37, 251-296, 2009.

VIGOTSKI, L. S. A brincadeira e o seu papel no desenvolvimento psíquico da criança. Revista Virtual de Gestáo de Iniciativas Sociais, v. 8, n.1, p. 23-36, 2008.

\section{Notas}

${ }^{1}$ A Idade em anos e meses; $\mathrm{b} F$ = feminino; $\mathrm{M}=$ masculino; $\mathrm{c}$ EI = Educação Infantil; EF = Ensino Fundamental.

${ }^{2}$ Cada dimensão totaliza $100 \%$, uma vez que suas categorias são mutuamente exclusivas.

${ }^{3}$ IDT = Irmão com desenvolvimento típico. ISD = Irmão com síndrome de Down.

${ }^{4}$ IDT = Irmão com desenvolvimento típico; ISD = Irmão com síndrome de Down.

\section{Correspondência}

Bruna Rocha de Almeida- Universidade Federal de Juiz de Fora (UFJF) Instituto de Ciência Humanas, Campus Universitário - Rua José Lourenço Kelmer, s/n - São Pedro, Juiz de Fora - MG, 36036-900

E-mail: bruna.r.almeida@gmail.com - naraliana.silva@uff.edu.br

Correspondência em 18 de julho de 2016

Final em 09 de outubro de 2017 
